\title{
Patient Safety in Cross-border Care
}

\author{
Eva TuRK, STEPHEN LEYSHON \& MORTEN PyTte
}

\begin{abstract}
Patient safety is a right and it raises particular issues in the context of cross-border care. Patients should be able to have trust and confidence in the healthcare structure as a whole; they must be protected from the harm caused by poorly functioning health systems, medical errors and adverse events. This paper addresses the state of cross-border healthcare in the European Union, the state of patient safety, the question of quality assurance and the role of accreditation as a risk based approach.
\end{abstract}

KEYWORDS: - patient safety $\cdot$ cross-border care $\cdot$ accreditation $\bullet$ healthcare $\bullet E U$

CoRRESPONDENCE AdDRESS: Eva Turk, Ph.D., Senior Researcher, DNV GL, Strategic Research and Innovation - Healthcare, Veritasveien 1, 1363 Høvik, Norway, email: eva.turk@dnvgl.com. Stephen Leyshon, M.Sc., DNV GL, Strategic Research and Innovation - Healthcare, Veritasveien 1, 1363 Høvik, Norway, email: stephen.leyshon@dnvgl.com. Morten Pytte, Ph.D., DNV GL, Strategic Research and Innovation - Healthcare, Veritasveien 1, 1363 Høvik, Norway, email: morten.pytte@ dnvgl.com.

DOI 10.18690/8.77-83(2015)

ISSN 2463-7955 Print (C) 2015 LeXonomica Press

Available online at http://journals.lexonomica.press. 
The aim of this paper is to highlight the patient safety challenges in cross-border care and the role of international accreditation and standards to reduce variability and improve safety.

This paper addresses the state of cross-border healthcare in the European Union, the state of patient safety, the question of quality assurance and the role of accreditation as a risk based approach We present the growing evidence on the benefits of accreditation, and share the learning from DNV GL's experience in other safety critical industries as well as our future research priorities.

\section{2}

\section{Cross-Border Care}

The majority of EU citizens receive healthcare in the Member State (MS) ${ }^{1}$ where they live, by belonging to the healthcare system via their tax payment or insurance. Nevertheless, EU patients have the right to obtain healthcare in another European country, where there may be lower costs, better expertise, and availability of specific highly specialised treatments or shorter waiting times. This right of EU citizens to access healthcare across borders has been one of the heavily debated health policy issues at EU level in recent years (Mc Kee et al, 2013). The Directive 2011/24/EU on patients' rights in cross-border healthcare, ${ }^{2}$ which was adopted on 9 March 2011, aims to clarify and simplify the rules and procedures applicable to patients' access to cross-border healthcare, provide EU citizens with better information on their rights, and promote cooperation between MS. Importantly, the Directive also aims to ensure that cross-border healthcare is safe and of high-quality.

\section{$3 \quad$ Why is patient's safety an issue?}

Healthcare across the globe is known to be dangerous to patients. Of the 421 million hospitalisations in the world annually, 42.7 million are estimated to be associated with some degree of adverse event - this makes unsafe care the " 14 th leading cause of morbidity and mortality, comparable to the burden from tuberculosis or malaria" (Jha et al., 2013). In the EU, an estimated $8-12 \%$ of patients admitted to hospital in the EU suffer from adverse events whilst receiving healthcare. The highest adverse events are healthcare-associated infections (accounting for approximately $25 \%$ of adverse events), followed by medicationrelated errors, surgical errors, medical device failures and errors in diagnosis, as well as failure to act on the results of tests. ${ }^{3}$ A recent Eurobarometer ${ }^{4}$ survey shows that over half (53\%) of all EU citizens think it is likely patients could be harmed by hospital care in their country. However, there is a wide variation in opinion across countries. While in Cyprus $82 \%$ of respondents do not trust their healthcare system, in Austria $21 \%$ of the respondents believe they could be harmed by national hospital care. Patient perceptions on healthcare quality differ. 
In the last 20 years, the problem of patient safety has become increasingly recognised and numerous studies around the globe have shown that patient safety issues know no borders. The problems and challenges we face are common in all countries (IOM, 2001; ), ${ }^{5},{ }^{6}$.

\section{$4 \quad$ The Question of Quality Assurance}

Healthcare carries an inherent risk of harm that cannot be eradicated but which must be continually reduced through quality assurance (Berwick, 2013). Patient safety is a right and it raises particular issues in the context of cross-border care. Patients should be able to have trust and confidence in the healthcare structure as a whole; they must be protected from the harm caused by poorly functioning health systems, medical errors and adverse events (Wismar et al, 2011). Much of the harm to patients is preventable, but the implementation of strategies to reduce harm varies widely across the EU. Important progress was made in many countries in terms of shaping national programmes for patient safety and putting in place systems to report adverse effects, though there is little information on their use or effectiveness. ${ }^{7}$ There is still a long way to go in terms of implementing provisions on patient empowerment and on education and training of healthcare workers. Approaches to optimising safety must include measures to detect adverse occurrences and to mitigate the harm they may cause. The task of developing new and more effective treatments must be complemented by an understanding of how to improve healthcare continuously and to build safer systems (Vincent, 2014).

Patient safety is a multifaceted issue and it raises the question of standards of healthcare and how these are to be framed. When patients are moving across the borders for healthcare, either for economic or professional reasons, challenges in less developed Member States still exist, and there is danger that safety standards might be compromised (Tingle, 2011). In addition to national commitment to ensuring patient safety and quality, international standards will increasingly have to play a role in assuring the quality and safety of patients in practice.

\section{$5 \quad$ Role of Accreditation as a Risk Based Approach}

Healthcare can be thought of as interacting complex systems, involving processes and people. There have been many efforts to improve patient safety. However, research suggests that more work is needed to address how people and groups think about, interact with, and are affected by the healthcare improvement innovations if there is to be sustained scale up and spread (Perla, 2013).

Risk based approaches can offer a way to tackle these 'softer issues' of the way in which people and socio-environmental factors interact. Risk thinking encompasses cyclical, continuous and dynamic processes of assessing hazards and selecting, implementing and evaluating controls to reduce the potential of those hazards 
from becoming harm (Leyshon, 2014). It offers a means to create safer, high quality care by addressing in structured, scientific ways human, technical and organisational issues, i.e. the nexus of factors and circumstances where preventable harm most often arises. In doing so, it supports the spread and sustainability of good practice, by enabling people to understand their local context; the nature of any innovation; and its planned cause and effect (including foreseeable positives and negatives).

Learning from other high risk sectors supports this (The Health Foundation , 2012). Responding to major disasters such as Flixborough ${ }^{8}$ and Piper Alpha (The Hon Lord Cullen, 1990), other sectors have made great strides in improving safety at a system level by using risk based approaches. They have been able to think ahead about what the obstacles and hazards might be; how those obstacles and hazards might prevent improvements or become harmful outcomes; and how systems can then best be designed to prevent or mitigate unintended results (The Health Foundation, 2012).

Accreditation is a programme of activity in which trained external peer reviewers evaluate an organization's compliance with pre-established standards (Alkhenizan and Shaw, 2011; WHO, 2003), that can be applied to specific areas (such as managing infection risk ${ }^{9}$ ) or across an organization's services. ${ }^{10}$ These iterative processes build on risk thinking by helping an organization to drive best practice in:

- Mapping processes (including how processes connect within and between organizations);

- Identifying and assessing risks to human, technological and organisational safety and performance;

- Establishing prevention and mitigation controls to deliver safe and reliable results; and

- Continuously monitoring to evaluate the efficacy of those controls.

\section{Evidence for accreditation}

In healthcare there is evidence that the use of system level methods to assess and manage risk improves quality. A recent EU funded MARQuIS study found that hospitals "that have either ISO certification or accreditation [i.e. hospitals that can demonstrate effective risk management] are safer and better than those which have neither" (Shaw, 2010). In a systematic review, Alkhenizan and Shaw, conclude “... that accreditation programs improve the process of care provided by healthcare services ... Accreditation programs should be supported as a tool to improve the quality of healthcare services" (Alkhenizan and Shaw, 2011: 410411). The "Deepening our understanding of quality improvement in Europe" (DUQuE) EU funded project assessed the relationship of organisational safety and quality improvement systems and culture, professionals' involvement, and patient empowerment with the quality of hospital care (Groene, Kringos and Sunol, 
2014). A particular focus was the role of external influences and governance on quality improvement strategies. The findings show that patient involvement in safety and quality management remains weak. Even when hospitals have succeeded in engaging patients this has seldom led to improvements in the care actually provided to patients (Groene et al, 2014a). Implementation of known safety strategies (such as those recommended by the WHO Patient's Safety Alliance, and national Patient Safety Agencies) is highly variable (Groene, Kringos and Sunol, 2014). This finding shows that countries have progressed at different rates but variation within countries is much larger than between countries. There is consistent evidence that accreditation can improve the process of care provided by healthcare services by improving the structure and organization of healthcare facilities (Groene, Kringos and Sunol, 2014). Accreditation is consistently related to promoting change and professional development.

\section{$7 \quad$ DNV GL's experience and Future Priorities}

Other safety critical sectors, such as oil and gas, have used risk based approaches to achieve significant and lasting improvements (Hudson, 2003): mapping and monitoring hazards, setting goals, and creating proportional cultural, structural and process controls. In DNV GL's 150 year experience, using risk based approaches can be a powerful way to drive improvements. To that end, from our analysis of the challenges, obstacles and strategic agenda, we have identified the following priorities for DNV GL's Strategic Healthcare Research and Improvement (figure 1) (Leyshon, 2014). These build on proven services that manage safety by combining cutting edge research with partners in areas that offer potentially the biggest impact for quality improvement.

Figure 1: Combining proven services to manage safety with cutting edge research themes to create safer and smarter healthcare

Creating smarter and safer healthcare together

Developing safety cases to manage risk locally

Improving assurance and prediction of quality with smarter data analysis

Creating cultures and mindsets that

embrace continuous quality improvement

Use of accreditation and standards to reduce variability and improve safety 


\section{Conclusions}

Patient safety has become a priority for almost all major healthcare systems in Europe. It is a multifaceted issue and it raises questions of standards of healthcare and how these can be framed. The field has matured considerably in the last decade both in terms of the scientific understanding of safety and in knowledge of the challenges of implementing practical safety programmes.

We now have a better understanding of the nature and scale of harm, the causes of error and, to a lesser extent, the solutions to these problems. There are two particular challenges in the coming years. The first will be to extend our safety knowledge and practice into care in the home and in the community. The second major challenge is to move from evidence of the effectiveness of specific projects to large scale implementation and sustained improvements of safety.

If further improvement in healthcare is to be realized then accreditation and standards must be at the forefront of pushing that change. Knowledge-based, international healthcare accreditation and standards can challenge healthcare to become safer, smarter, sustainable and person-centered while coping with the local contextual demands.

\footnotetext{
Notes

${ }^{1}$ The Member States of the European Union plus Iceland, Liechtenstein and Norway.

${ }^{2}$ http://eur-

lex.europa.eu/LexUriServ/LexUriServ.do?uri=OJ:L:2011:088:0045:0065:EN:PDF.

${ }^{3} \mathrm{http} / / /$ ec.europa.eu/health/patient_safety/policy/index_en.htm.

${ }^{4} \mathrm{http}: / /$ ec.europa.eu/health/patient_safety/docs/ebs_411_en.pdf.

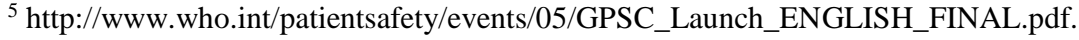

${ }^{6}$ www.eunetpas.eu.

${ }^{7}$ http://ec.europa.eu/health/patient_safety/docs/council_2009_report_en.pdf.

${ }^{8}$ Health and Safety Executive (1975) The Flixborough disaster: Report of the Court of Inquiry London: HMSO. Ni med viri???

9 See, for example, DNV GL's Managing Infection Risk - available here: www.dnvaccreditation.com/pr/dnv/managing-infection-risk-243091.aspx - last accessed 30th November 2013.

10 See, for example, DNV GL's Hospital Accreditation - available here: www.dnvaccreditation.com/pr/dnv/default.aspx - last accessed 30th November 2013.
}

\section{References}

Alkhenizan, A. \& Shaw, C. (2011) Impact of accreditation on the quality of healthcare services: a systematic review of the literature Annals of Saudi Medicine, 31(4), pp. 407416, doi: 10.4103/0256-4947.83204.

Berwick, D. M. (2013) A promise to learn - a commitment to act. Improving the safety of patients in England. (London, Department of Health), available at: https://www.gov.uk/government/uploads/system/uploads/attachment_data/file/226703/ Berwick_Report.pdf (February 3, 2015). 
Groene, O., Kringos, D. \& Sunol, R. (2014) Seven ways to improve quality and safety in hospitals. An evidence-based guide (Barcelona: DUQuE Collaboration), available at http://www.duque.eu/uploads/DUQuE_Seven_Ways_To_Improve_Quality_And_Safet y_2014.pdf (January 18, 2015).

Groene, O., Sunol, R., Klazinga, N. S., Wang, A., Dersarkissian, M., Thompson, C. A., \& Thompson, C. A. (2014a) Involvement of patients or their representatives in quality management functions in EU hospitals: implementation and impact on patient-centred care strategies, International Journal for Quality in Health Care, 26(suppl 1), pp. 8191, doi: 10.1093/intqhe/mzu022.

Hudson (2003) Applying the lessons of high risk industries to healthcare, Quality \& Safety in Health Care, 12(sup. 2) pp i7-i12.

IOM (2001) Crossing the quality chasm: A new health system for the 21st century (Washington, DC: National Academy Press).

Jha, A. K., Larizgoitia, I., Audera-Lopez, C., Prasopa-Plaizier, N., Waters, H., \& Bates, D. W. (2013) The global burden of unsafe medical care: analytic modelling of observational studies, BMJ Quality \& Safety, 22(10), pp. 809-815, doi: 10.1136/bmjqs2012-001748.

Leyshon, S., Turk, E., Pytte, M., Listyowardojo, T. A., Lyons, M., Torhaug, R., McAdam, S., Timmons, K. \& Fløysand, C. (2014) Healthcare 2050: a vision of safer and smarter health services: DNV GL strategic research \& innovation position paper 3-2014 (Høvik: DNV GL).

Leyshon, S., Turk, M., Pytte, M., McAdam, S. \& Vincent, C. (2013) Distilling the Lessons - European Workshop on Risk Management for Patient Safety (Høvik: DNV).

McKee, M., Busse, R., Baeten, R. \& Glinos, I. (2013) Cross-Border Healthcare Collaboration in the European Union: Placing the Patient at the Centre, Eurohealth incorporating Euro Observer, 19(4), pp. 3-5.

Perla, R. J., Bradbury, E. \& Gunther-Murphy, C. (2013) Large scale improvement initiatives in healthcare: a scan of the literature, Journal for healthcare quarterly, 35(1), pp. 30-40, doi: 10.1111/j.1945-1474.2011.00164.x.

Shaw, C., Groene, O., Mora, N. \& Sunol, R. (2010) Accreditation and ISO certification: do they explain differences in quality management in European hospitals? International Journal for Quality in Health Care, 22(6), pp. 445-451, doi: 10.1093/intqhe/mzq054..

The Health Foundation (2012) Using safety cases in industry and health care (London: The Health Foundation).

The Hon Lord Cullen (1990) The Public Inquiry into the Piper Alpha disaster - Volumes I \& II (London: Department of Energy).

Tingle, J., Bark, P. (eds.) (2011) Patient Safety, Law Policy and Practice (London: Routledge).

Vincent, C., Turk, E., Listyowardojo,T. A, Pytte M, McAdam S, Leyshon S. (2014) Taking stock : report of a European workshop on priorities in risk management for patient safety. (Høvik: DNV GL).

WHO (2003) Quality and accreditation in health care services - a global review (Geneva: WHO).

Wismar, M., Palm, W., Figueras, J., Ernst, K., \& Van Ginneken, E. (eds.) (2011) Crossborder health care in the European Union: mapping and analysing practices and policies Geneva: World Health Organization) 